\title{
Testing soil water repellency in a Sicilian area two years after a fire
}

\author{
Vincenzo Bagarello, ${ }^{1}$ Giuseppe Basile, ${ }^{2}$ Gaetano Caltabellotta, ${ }^{1}$ Giuseppe Giordano, ${ }^{1}$ Massimo Iovino ${ }^{1}$ \\ ${ }^{1}$ Dipartimento di Scienze Agrarie, Alimentari e Forestali, Università degli Studi di Palermo; ${ }^{2}$ Centro Funzionale \\ Decentrato della Regione Siciliana, Dipartimento della Protezione Civile, Regione Siciliana, Palermo, Italy
}

\begin{abstract}
The water drop penetration time (WDPT) technique was applied in 2018 to check persistence of soil water repellency (SWR) in a Sicilian mountain area affected by a wildfire on June 2016. A total of four sites, that were severely water repellent immediately after burning, were sampled. Depending on the site, wettable soil conditions, less SWR and maintenance of a noticeable SWR were detected two years later. At the site showing a near-constant SWR, WDPTs were particularly high in the top soil layer $(0-0.03 \mathrm{~m})$ and they appreciably decreased more in depth. Signs of decreasing SWR in drier soil conditions and in association with coarser soil particles were also detected at this site. High gradients of the WDPT can occur at very small vertical distances and a depth increment of approximately $0.01 \mathrm{~m}$ should be appropriate to capture small-scale vertical changes in SWR, especially close to the soil surface. Occurrence of SWR phenomena is easily perceivable and explainable if an inverse relationship between WDPTs and antecedent soil water content is obtained. A direct relationship between these two variables is more difficult to interpret because infiltration times that increase in wetter soil are expected according to the classical infiltration theory. A hypothesis that should be tested in the future is to verify if WDPTs that decrease in drier soil conditions signal less SWR as a consequence of a reduced biological activity of the soil. Finally, long-term monitoring projects on longevity of fire effects on SWR should be developed, even because an in depth knowledge of the involved processes is relevant for the civil protection system.
\end{abstract}

Correspondence: Massimo Iovino, Dipartimento di Scienze Agrarie, Alimentari e Forestali, Università degli Studi di Palermo, Ed. 4, viale delle Scienze, 90128 Palermo, Italy.

E-mail: massimo.iovino@unipa.it

Key words: Fire-induced soil water repellency; water drop penetration time technique; temporal persistence; field and laboratory investigations.

Received for publication: 6 June 2019.

Accepted for publication: 21 September 2019.

CCopyright: the Author(s), 2020

Licensee PAGEPress, Italy

Journal of Agricultural Engineering 2020; LI:988

doi:10.4081/jae.2019.988

This article is distributed under the terms of the Creative Commons Attribution Noncommercial License (by-nc 4.0) which permits any noncommercial use, distribution, and reproduction in any medium, provided the original author(s) and source are credited.

\section{Introduction}

Soil water repellency (SWR) reduces the affinity of soils to water such that they resist wetting for periods ranging from a few seconds to hours, days or weeks (Doerr et al., 2000). Water repellency of fire affected soils can have adverse impacts on slope hydrology and soil erosion as a consequence of the reduced wettability of soils that impedes infiltration and enhances surface runoff (Alagna et al., 2019). The civil protection system has specific interest for fire effects due to the possible consequences of burning events on both landscape instability and risks of flooding, especially near vulnerable assets such as residential and touristic areas, roads and industries. Predicting fire effects on soils is complicated because many factors, including fire severity, soil temperature gradient, vegetation type, fuel amount and soil characteristics, influence SWR that can develop following fire passage (e.g., Tessler et al., 2008; Tinebra et al., 2019).

Fire induced SWR is expected to decrease with time and it should break down within a few months to a couple of years (Doerr et al., 2009) although an appreciably longer persistence of fire effects, even for 5 to 14 years, was also reported (Robichaud et al., 2013). Doerr et al. (2006) signalled a lack of attention to the longevity of fire effects but several investigations on temporal persistence of fire induced SWR were carried out afterwards (e.g., Keizer et al., 2008; Tessler et al., 2008; Larson-Nash et al., 2018; Tinebra et al., 2019). More data contributed to better establish what can happen after the passage of a fire. For example, Tinebra et al. (2019) recently recognized that SWR persistence depended on the severity of the wildfire. In particular, a moderate fire induced a severe hydrophobicity soon after the event but this hydrophobicity tended to decrease or even vanish within approximately one year. With a stronger wildfire, the SWR break down did not occur at the same rate detected for a less severe wildfire. The persistence of post-fire SWR can be highly variable even for a particular vegetation type and geographic area (Doerr et al., 2009) and there can be situations in which SWR appears unpredictable (Dekker et al., 2001). Therefore, collecting other SWR data at different times after the passage of a fire appears necessary to further improve knowledge of post fire SWR processes.

A large number of factors have been shown to influence local measurements of SWR, such as soil water content (de Jonge et al., 1999; Dekker et al., 2001; Gao et al., 2018), presence or absence of vegetation cover on the soil surface (Doerr and Thomas, 2000; Oostindie et al., 2017), sample disturbance (Graber et al., 2006; Weninger et al., 2019), soil compaction (Bryant et al., 2007), considered particle size fractions when working on sieved soil (Bisdom et al., 1993; Rodríguez-Alleres et al., 2007), depth along the soil profile (Wallach et al., 2005; Alagna et al., 2017; LarsonNash et al., 2018). Consequently, another reason why explanation of SWR processes in fire affected areas is not easy is that the available information on the effects of a given factor on SWR is 
not, and perhaps cannot be, unequivocal. This is the case, for example, of soil water content since de Jonge et al. (1999) reported that three different relationships between SWR and soil water content could experimentally be obtained: i) no water repellency at any soil water content; ii) no water repellency at very low water contents after oven drying but water repellency as soil water content increases; and iii) water repellency for two different, low water content values but wettability for intermediate water contents between these two values. According to Dekker et al. (2001), a transition zone of soil water contents can be recognized, in which the soil can either be wettable or water repellent. Soil water contents below and above the boundaries of the transition zone define the actually water repellent and wettable situations, respectively. Effects of soil depth and particle size on SWR can also be expected to vary locally. Larson-Nash et al. (2018) suggested that fire induced SWR should occur 0.01 to $0.03 \mathrm{~m}$ below the soil surface but, in the investigation by Weninger et al. (2019), SWR was detected at the soil surface and not at a depth of $0.01 \mathrm{~m}$ nor when the authors used sieved soil instead of undisturbed soil. Small particle size fractions can exhibit more SWR than coarse fractions (de Jonge et al., 1999) but the relationship between SWR and soil particle size can also depend on land use (Rodríguez-Alleres et al., 2007). The large variety of situations that can occur probably represents one of the reasons still impeding development of a framework for the quantitative evaluation and classification of SWR (Weninger et al., 2019).

Among different methods that can be used to check SWR (Doerr, 1998; Lichner et al., 2018; Weninger et al., 2019), the water drop penetration time (WDPT) test (Doerr, 1998; Letey et $a l ., 2000$ ) has been, and continues to be, widely applied to quantify SWR since the experiment is very easy, reasonably rapid and it yields a valuable information on SWR (Dekker et al., 2009; Alagna et al., 2017; Iovino et al., 2018). The technique has been used with different application methodologies (e.g., Keizer et al., 2008; Gordillo-Rivero et al., 2014; Alagna et al., 2017; Oostindie et al., 2017), due to the unavailability of a standard WDPT procedure (Hallin et al., 2013), and different approaches have also been used to summarize the WDPT values collected in a small area or at a near point location. For example, both Bisdom et al. (1993) and Gordillo-Rivero et al. (2014) used three drops in their experiments but the median WDPT was calculated in the former case to summarize the data while the mean was determined in the latter case. However, Doerr et al. (2009) did not recommend the use of the mean since it can greatly be affected by one or a few drops with very long penetration times. According to these authors, the median should generally be considered the most accurate index of SWR. An implication of this conclusion could be that Bisdom et al. (1993) provided a more reliable information than GordilloRivero et al. (2014). However, the mean WDPT continues to be used (e.g., Tinebra et al., 2019), probably because it is still unclear if the recommendation by Doerr et al. (2009) has a general validity. An extensive wildfire occurred in summer 2016 in the natural reserve area of Mount Pellegrino (Sicily, Italy), dominating the city of Palermo. The need to safeguard the inhabitants of the city stimulated a rapid and extensive assessment of SWR following the wildfire, that was carried out by Tinebra et al. (2019) two months after the fire and, in a few selected sites, repeated also in 2017. In particular, a total of 93 sites were sampled with the WDPT technique in 2016 and a link between fire severity and SWR was recognized.

In this investigation, SWR was determined in the already sampled natural reserve area of Mount Pellegrino two years after the passage of the fire with the following objectives: i) to verify temporal changes in SWR by field application of the WDPT technique in the sites showing the greatest SWR soon after the fire; and ii) to check depth, soil water content and particle size effects on SWR in the laboratory for a site that showed clear signs of persisting water repellency two years after the fire.

\section{Materials and methods}

\section{Field area and choice of the sampling sites}

The investigation was carried out in the natural reserve area of Mount Pellegrino (elevation of $606 \mathrm{~m}$ a.s.1.), located in the coastal zone of north-western Sicily, between the city of Palermo and its beach zone of Mondello. The reserve was burnt by a wildfire on June 16, 2016. Water repellency at the soil surface was determined with the WDPT technique (Bisdom et al., 1993; Doerr, 1998; Hallin et al., 2013) in summer of 2016, that is approximately 1.5 2 months after the fire, at 93 sampling sites distributed throughout the reserve, and a few selected sites were sampled again in the spring of 2017 (Tinebra et al., 2019).

The sites to be sampled in this investigation (Table 1) were

Table 1. Characteristics of the four sampled sites.

\begin{tabular}{|c|c|c|c|c|}
\hline Parameter & Site 36 & Site 40 & Site $42 *$ & Site 55 \\
\hline Coordinates & 33S 0356667 UTM 4223913 & 33S 0355985 UTM 4224423 & 33S 0355919 UTM 4224479 & 33S 0355609 UTM 4226187 \\
\hline Elevation (m a.s.l.) & 169 & 295 & 291 & 429 \\
\hline Aspect & South & West & South-West & South \\
\hline Tree species in June 2016 & $\begin{array}{c}\text { Pinus pinea } \\
\text { Pinus halepensis } \\
\text { Opuntia ficus indica } \\
\text { Eucalyptus camaldulensis }\end{array}$ & $\begin{array}{l}\text { Pinus pinea } \\
\text { Pinus halepensis }\end{array}$ & Pinus halepensis & $\begin{array}{l}\text { Pinus pinea } \\
\text { Eucalyptus camaldulensis }\end{array}$ \\
\hline Clay (\%) & 16.0 & 11.9 & 24.0 & 26.6 \\
\hline Silt (\%) & 58.3 & 50.9 & 59.4 & 51.6 \\
\hline Sand (\%) & 25.7 & 37.2 & 16.5 & 21.8 \\
\hline Soil textural class (USDA) & Silt-loam & Silt-loam & Silt-loam & Silt-loam \\
\hline
\end{tabular}

*Clay, silt and sand percentages and soil textural classification for the site 42 from Tinebra et al. (2019). 
chosen on the basis of the data collected in 2016 by Tinebra et al. (2019). In particular, the WDPTs of the applied droplets were summed for each of the 93 sites, assuming WDPT $=3600 \mathrm{~s}$ in the few cases with WDPT $>3600 \mathrm{~s}$, and the four sites with the highest totals of WDPT values (sites 36, 40, 42 and 55) were selected. All these sites were severely water repellent in 2016 . For each site, soil textural characteristics (USDA classification scheme) were determined with standard methodologies (e.g., Gee and Bauder, 1986) on at least two replicated surface soil samples (Table 1).

\section{Soil water repellency two years after the fire}

The applied experimental procedure to detect in the field signs of SWR two years after the fire was similar for the four sites (36, 40, 42 and 55) but the site 42 was sampled more intensively than the other sites. The reason was that more experimental information was available for this site than the other ones at the beginning of this investigation (Tinebra et al., 2019). This circumstance was favorable to develop a field dataset potentially yielding a relevant information on the factors that locally influenced SWR. The mean organic matter, $O M$, content of the upper soil layer at the site 42, determined on April 2018 with the Walkley-Black method, was equal to $6.4 \%$ (coefficient of variation, $C V=20.9 \%$; sample size, $N=3$ ). A comparison between the two sampling years, i.e. 2016 and 2018, was carried out under similar climatic conditions and applied experimental methodology for the two years. Consequently, the field work was carried out in late July 2018, to consider dry soil and hot summer conditions in both years (Dekker et al., 2011), and SWR was assessed by exactly the same procedure by Tinebra et al. (2019). The mineral soil surface was gently exposed by a spatula immediately before the WDPT test and 16 water drops of $0.05 \mathrm{~mL}$ were applied on a square area of the soil surface at a mutual distance of $1 \mathrm{~cm}$ from a height of approximately $1 \mathrm{~cm}$. As a noticeable SWR was detected at site 55 in 2018, a duplicate experiment (55a and 55b) was carried out in this site, at a mutual distance of just a few dozens of centimeters.

Surface soil at the site 42 was repeatedly sampled during the April to July months of 2018 since data were collected in both summer 2016 and spring 2017 by Tinebra et al. (2019). In particular, soil was sampled on mid-April (code of the experiment I) using 100 droplets, immediately after gently exposing the mineral soil with a spatula. One month later (mid-May), exactly the same area was sampled again with the same experimental methodology (experiment II), and two additional WDPT experiments were carried out in the neighbourhoods, i.e. at a few dozens of centimeters from the already sampled area. In particular, the experiment was repeated on another portion of the previously exposed soil surface using the same number of droplets (100, experiment III). These data were collected because SWR can vary over short distances (e.g., Dekker et al., 2009) but the sampled area for a near-point characterization of SWR is often chosen rather arbitrarily. Comparing different near-point areas was a way to check the influence of this arbitrariness on SWR assessment in the field. The same experiment with 100 droplets was also performed on another zone in which vegetation and litter were removed a few dozens of minutes before applying the droplets (experiment IV). This additional experiment was carried out to verify if the time interval between exposure of the soil surface to be sampled and WDPT experiment should be expected to influence SWR assessment (Oostindie et al., 2017). The soil was then re-sampled in late June using 100 droplets. This experiment (V) was carried out in exactly the same bare area sampled in the previous two months but another experiment (VI) was carried out close to this area, again by removing the vegetation only a few dozens of minutes before performing the WDPT test. Finally, the sampling of late July represented the VII experiment at the site 42.

Each field experiment was carried out on a square area with a side length $\leq 1 \mathrm{~m}$, in accordance with Tinebra et al. (2019). Using 16 drops at a site was consistent with the previous investigation by these authors, in which there was the need to sample many sites soon after the burning event. A larger number of drops was used to make some additional checks (e.g., small scale spatial variability, vegetation effects), to possibly improve the robustness of the locally collected information. According to the general recommendations by Hallin et al. (2013), 30 and eight drops are enough to confidently estimate the mean WDPT and the SWR class, respectively. The results previously obtained by Tinebra et al. (2019) at the field site confirmed that 16 drops were enough to characterize a site. Therefore, the expectation was to obtain a reliable information for each field experiment of this investigation. For each site and for each sampling date at the site 42 , the gravimetric soil water content, $w_{i}\left(\mathrm{~g} \mathrm{~g}^{-1}\right)$, at the time of the WDPT experiment was determined in the laboratory on three to five soil samples randomly collected close to the sampled area from the upper $0.02 \mathrm{~m}$ of the profile.

\section{Depth, water content and particle size effects on soil water repellency}

Soil water repellency was investigated in some detail at the site 55 since the surface soil of this site was found to be water repellent in 2018. In particular, depth (Wallach et al., 2005; Graber et al., 2006; Alagna et al., 2017; Weninger et al., 2019), water content (de Jonge et al., 1999; Doerr and Thomas, 2000; Dekker et al., 2001; Gao et al., 2018) and particle size (Bisdom et al., 1993; de Jonge et al., 1999; Rodríguez-Alleres et al., 2007) effects on SWR were checked. For both the 55a and 55b sites, six undisturbed soil cores of $5 \mathrm{~cm}$ in height and diameter were collected on July 2018 from randomly selected points on the surface and they were transported in the laboratory and immediately weighted to later determine their gravimetric soil water content at the beginning of the laboratory experiment. Four drops were applied on the surface soil layer of a given soil core and their infiltration time was measured. The same procedure was applied at other four depths, i.e. $-1,-2,-3$ and -4 $\mathrm{cm}$ for each core. To allow measurements on deeper layers, soil was pressed out of the core from the bottom by a plug and the upper layer was removed with a knife (Wallach et al., 2005; Graber et al., 2006). Each sample was exposed to air for one or two days after exposure of the subsequent soil layer in the sequence to reduce possible gradients in initial soil water conditions between layers (Weninger et al., 2019). The experiments failed for two cores of the site $55 \mathrm{~b}$ at the $-4 \mathrm{~cm}$ depth due to the rupture of the soil sample while pressing out.

On December 2018, a total of 35 undisturbed soil cores of $2 \mathrm{~cm}$ in height and $5 \mathrm{~cm}$ in diameter were collected from randomly established points on the soil surface of the site 55a and they were transported in the laboratory and randomly subdivided into five groups, each of seven cores. The five groups were subjected to the following different drying treatments before performing the WDPT test: i) one week of air drying; ii) one month of air drying; iii) two months of air drying; iv) oven drying at $60^{\circ} \mathrm{C}$ for $48 \mathrm{~h}$ and then exposure to air for other $48 \mathrm{~h}$; and v) oven drying at $105^{\circ} \mathrm{C}$ for $48 \mathrm{~h}$ and then exposure to air for other $48 \mathrm{~h}$. After the pre-treatment, four drops were applied on the surface soil layer of a given soil core and their infiltration time was measured. All cores were weighted before applying the droplets to later determine $w_{i}$ for each individual soil core.

On December 2018, disturbed soil was also collected at the site 
55a to a depth of 0.03-0.04 m. The soil was transported to the laboratory where it remained exposed to air for approximately two months Then, the soil was manually crumbled and mechanically passed through the $2.0 \mathrm{~mm}$ sieve. Mechanical sieving was subsequently used to subdivide part of the $<2.0 \mathrm{~mm}$ soil mass into four size fractions, i.e. $<0.25 \mathrm{~mm}$ (representing the $12.7 \%$ of the fine soil), 0.25-0.425 mm (15.3\%), 0.425-0.85 mm (25.7\%), and 0.85$2.0 \mathrm{~mm}(46.3 \%)$. The Walkley-Black method was applied to determine the $O M$ content for each of these four fractions. Therefore, a total of five soil textural fractions were prepared. Each soil fraction was placed in a plate with a diameter of nearly $30 \mathrm{~cm}$ and a height of $1.5 \mathrm{~cm}$, that was filled and gently pressed up to the upper rim. A total of 102 droplets were applied to each soil fraction and their infiltration times were measured. The WDPT experiment was carried out the day after sieving the soil. The gravimetric water content of each soil fraction was determined before applying the droplets to the soil. Soil equilibrated with the laboratory air humidity was used for this experiment since this is a rather common condition in laboratory determinations of SWR (Bisdom et al., 1993; Gordillo-Rivero et al., 2014).

\section{Soil water repellency classification}

One of the objectives of this investigation was to establish a comparison with the information obtained in 2016 by Tinebra et al. (2019). For methodological consistence, the repellency class was therefore determined for each applied droplet at a site according to Bisdom et al. (1993) (wettable soil, WET, WDPT <5 s; slightly water repellent, SLI, 5-60 s; strongly water repellent, STR, 60-600 s; severely water repellent, SEV, 60-3600 s; extremely water repellent, EXT, $>3600 \mathrm{~s}$ ) and the repellency class for the site was assumed to be the mode of the locally determined SWR classes. The availability of a relatively large number of samples with many replicated measurements of WDPT implied the possibility to also check the suggestion by Doerr et al. (2009) to use the median WDPT to characterize small scale SWR. In particular, eight samples, each having a sample size $N=100$, were obtained directly in the field at the site 42, in part by Tinebra et al. (2019), and five samples with $N=102$ were obtained in the laboratory on sieved soil for the particle size effect experiment. For each sample, the normal distribution hypothesis of the WDPT was therefore checked by the Lilliefors (1967) test at $\mathrm{P}=0.05$. For these 13 samples, a comparison was then established between the mode of the SWR classes determined for each droplet (Tinebra et al., 2019) and the SWR class that was associated to the median WDPT value.

\section{Results and discussion}

\section{Statistical distribution of the water drop penetration times}

The normal distribution hypothesis of the WDPT values was rejected in 12 of the 13 tested cases, supporting the suggestion by Doerr et al. (2009) that the arithmetic mean of the experimental WDPT values is not the best index to summarize a set of data. According to these authors, the median of the WDPT values was therefore calculated in this investigation to estimate the central tendency of a sample distribution.

\section{Soil water repellency two years after the fire}

The sites 36 and 40, that were severely water repellent in 2016, were found to be wettable two years later (Table 2). The severe water repellency detected at the site 55 in 2016 did not disappear in 2018 since the soil was found to be severely or strongly water repellent, depending on the specifically sampled area $(55 \mathrm{a}$ or $55 \mathrm{~b}$, respectively). At the site 42, the same information on SWR was always obtained by considering either the modal class for the applied droplets (Tinebra et al., 2019) or the SWR class associated with the median WDPT value (Table 3). According to this result, two investigations differing by the applied method to summarize the data (modal class, median WDPT) should be expected to be comparable. The soil at this site was found to be severely or even extremely water repellent by Tinebra et al. (2019) in 2016 and 2017 (Table 3) and it was strongly water repellent on April 2018 (experiment I). A possible effect of the initial soil water content on the detected decrease of SWR appeared possible since many studies indicated that soils can be more repellent when dry and less repellent or non-repellent when moist (de Jonge et al., 1999; Doerr and Thomas, 2000; Dekker et al., 2001) and the soil was 3.7 times wetter on April 2018 (0.242 $\left.\mathrm{g} \mathrm{g}^{-1}\right)$ than on May $2017\left(0.065 \mathrm{~g} \mathrm{~g}^{-1}\right)$. However, the subsequent experiment (II) did not support this interpretation because the soil was drier $\left(0.136 \mathrm{~g} \mathrm{~g}^{-1}\right)$ but also wettable and this information did not change for experiment III, which also indicated that the sampled area at a site did not affect SWR classification. On the other hand, clear signs of a strong water repellency, similar to those obtained in April, were detected during the same sampling campaign (May 2018) when the vegetation was removed immediately before performing the WDPT measurements (experiment IV). In this case, the upper soil layer had an initial water content of $0.205 \mathrm{~g} \mathrm{~g}^{-1}$, suggesting that maintaining the vegetation cover on the soil surface reduced its drying rate. A similar information was obtained on June since $w_{i}=0.106$ and $0.129 \mathrm{~g} \mathrm{~g}^{-1}$ were obtained for the soil surface exposed on April and

Table 2. Comparison between soil water repellency assessment in 2016 and 2018 at the 36, 40 and 55 sites.

\begin{tabular}{|c|c|c|c|c|c|c|c|}
\hline \multirow{2}{*}{ Wetness and soil water repellency class } & \multicolumn{2}{|c|}{ Site 36} & \multicolumn{2}{|c|}{ Site 40} & \multicolumn{3}{|c|}{ Site 55} \\
\hline & 2016 & 2018 & 2016 & 2018 & 2016 & $2018(55 a)$ & $2018(55 b)$ \\
\hline$w_{i}\left(\mathrm{~g} \mathrm{~g}^{-1}\right)$ & & 0.052 & & 0.044 & & 0.116 & 0.090 \\
\hline Wettable, WET & 0 & 16 & 0 & 15 & 0 & 0 & 0 \\
\hline Slightly water repellent, SLI & 0 & 0 & 0 & 1 & 0 & 0 & 5 \\
\hline Strongly water repellent, STR & 4 & 0 & 1 & 0 & 3 & 0 & 11 \\
\hline Severely water repellent, SEV & 10 & 0 & 13 & 0 & 11 & 15 & 0 \\
\hline Extremely water repellent, EXT & 2 & 0 & 2 & 0 & 2 & 1 & 0 \\
\hline
\end{tabular}

$w_{i}$, antecedent gravimetric soil water content. Values in italics indicate the modal number of droplets. 
the exposed surface immediately before performing the WDPT experiment, respectively. Wettable conditions were detected in both experiments (V and VI) of June. However, working on a soil surface exposed two months before performing the WDPT experiment determined the immediate infiltration of all droplets whereas removing the vegetation in proximity of droplets application implied that the $50 \%$ of the droplets needed $>5$ s to infiltrate the soil. Finally, clearly wettable conditions were obtained in July (experiment VII) on an initially very dry soil $\left(w_{i}=0.046 \mathrm{~g} \mathrm{~g}^{-1}\right)$.

Soil water repellency can change markedly within short to very short, i.e. even weeks, periods (Keizer et al., 2008; Tessler et al., 2008) and several studies suggested that the increase in SWR due to burning should break down within a period varying from a few months to a couple of years (Doerr et al., 2009). This investigation was consistent with such a suggestion since the WDPT experiments performed in 2018 indicated in most cases, i.e. with the exception of the site 55, less water repellency, or even disappearance of any water repellency, as compared with the SWR observed in the two previous years.

With reference to the site 42 , the time interval between removal of vegetation cover and litter from the soil surface and the WDPT test appeared to influence the collected experimental information. More clearly on an occasion (May) and less clearly, but still perceptibly, on another occasion (June), clearing the soil surface only a short time before performing the test signalled more SWR than that detected on a soil surface that remained bare for one or two months. A similar result was also obtained by Oostindie et al. (2017) who however also reported higher soil water content in the bare versus the grass-covered plots. Perhaps, the opposite result was obtained for soil water content in this investigation (Table 3) because sampling was carried out in late spring or summer and vegetation did not contribute appreciably to soil water depletion, i.e. it mainly influenced evaporation rates from the soil surface but not, or only marginally, transpiration.

In this sampling campaign, signs of SWR were detected for relatively high $w_{i}$ values $\left(0.21-0.24 \mathrm{~g} \mathrm{~g}^{-1}\right)$ whereas wettability was consistently detected in drier soil conditions $\left(w_{i}=0.05-0.14 \mathrm{~g} \mathrm{~g}^{-1}\right)$. In particular, the bare area after its exposure to air of April experienced a steady decrease in soil water content (from 0.24 to $0.05 \mathrm{~g} \mathrm{~g}^{-1}$; experiments I, II and III, V, and VII, Table 3) and it showed SWR only in the initially wettest condition.

A possible explanation of this result could be that, in 2018, the soil was not water repellent and soil capillarity had a decreasing impact on wetting rates as the initial soil water content increased. Consequently, infiltration rates were smaller in initially wetter conditions. However, different interpretations also appeared possible starting from the fact that the experiment was carried out on a four months period during which, perhaps, SWR changed inherently. Another reason why the data could be considered to contain an information related to SWR dynamics was that less water repellency of drier soils does not represent a physically impossible result (de Jonge et al., 1999; Gao et al., 2018). Moreover, Doerr and Thomas (2000) suggested that re-establishment of repellency after wetting may require a fresh input of water repellent substances and, in this investigation, smaller WDPT values were obtained in the area exposed on April, that did not receive any input of repellent substances after removing vegetation.

\section{Depth, water content and particle size effects on soil water repellency}

\section{Depth}

All possible classes of SWR were detected at the sites 55a and $55 \mathrm{~b}$ and the variability in WDPT values at a given depth varied from more than two orders of magnitude to more than four orders magnitude (Figure 1A and B). Similar levels of variability were reported by Wallach et al. (2005) for a soil in which water repellency had another origin (irrigation with treated sewage effluent). According to the median WDPTs for each sampling depth, the SWR decreased with depth from extreme to slight at the site 55a (Figure 1A) and from strong to slight at the site 55b (Figure 1B). This laboratory investigation suggested that, at the soil surface, the site $55 \mathrm{~b}$ was less water repellent than the site 55a (Figure 1C) and this result was consistent with that previously obtained directly in the field (Table 2). The two sites had more similar repellency characteristics at the greatest depths. The soil layer affected by an extreme water repellency was thinner than the strongly water repellent layer.

Table 3. Experimental details and results of soil water repellency assessment by the water drop penetration time experiments carried out at the site 42 in the 2016 to 2018 years.

\begin{tabular}{|c|c|c|c|c|c|c|c|c|c|c|}
\hline $\begin{array}{l}\text { Sampling campaign } \\
\text { Date }\end{array}$ & $\begin{array}{l}\text { Tine } \\
\text { Aug } \\
2016\end{array}$ & $\begin{array}{c}\text { ra et al. } \\
\text { May } \\
2017\end{array}$ & $\begin{array}{l}\text { May } \\
2017\end{array}$ & $\begin{array}{c}\text { I } \\
\text { Apr } \\
2018\end{array}$ & $\begin{array}{c}\text { II } \\
\text { May } \\
2018\end{array}$ & $\begin{array}{c}\text { III } \\
\text { May } \\
2018\end{array}$ & $\begin{array}{c}\text { IV } \\
\text { May } \\
2018\end{array}$ & $\begin{array}{c}\text { V } \\
\text { Jun } \\
2018\end{array}$ & $\begin{array}{c}\text { VI } \\
\text { Jun } \\
2018\end{array}$ & $\begin{array}{c}\text { VII } \\
\text { Jul } \\
2018\end{array}$ \\
\hline Number of droplets & 16 & 100 & 100 & 100 & 100 & 100 & 100 & 100 & 100 & 16 \\
\hline $\begin{array}{l}\text { Time between vegetation } \\
\text { removal and WDPT test }\end{array}$ & Minutes & Minutes & Minutes & Minutes & One month & One month & Minutes & Two months & Minutes & $>$ Three months \\
\hline$w_{i}\left(\mathrm{~g} \mathrm{~g}^{-1}\right)$ & n.d. & 0.065 & 0.065 & 0.242 & 0.136 & 0.136 & 0.205 & 0.106 & 0.129 & 0.046 \\
\hline Wettable, WET & 0 & 0 & 0 & 1 & 81 & 100 & 0 & 100 & 50 & 16 \\
\hline Slightly water repellent, SLI & 0 & 0 & 0 & 36 & 16 & 0 & 10 & 0 & 46 & 0 \\
\hline Strongly water repellent, STR & 0 & 10 & 21 & 47 & 2 & 0 & 50 & 0 & 4 & 0 \\
\hline Severely water repellent, SEV & 14 & 37 & 53 & 16 & 1 & 0 & 36 & 0 & 0 & 0 \\
\hline Extremely water repellent, EXT & 2 & 53 & 26 & 0 & 0 & 0 & 4 & 0 & 0 & 0 \\
\hline Median WDPT (s) & n.d. & 3804.5 & 1740.0 & 136.5 & 2.0 & 1.0 & 396.0 & 1.0 & 4.5 & 1.0 \\
\hline SWR class (modal class) & SEV & EXT & SEV & STR & WET & WET & STR & WET & WET & WET \\
\hline SWR class (median WDPT) & n.d. & EXT & SEV & STR & WET & WET & STR & WET & WET & WET \\
\hline
\end{tabular}

WDPT, water drop penetration time; n.d., not determined; SWR, soil water repellency. 
The decrease of SWR with depth was probably associated with decreasing organic matter and previous fire burning effect, as suggested by Weninger et al. (2019). Possible initial soil water content effects on the vertical profile of SWR were considered less probable because procedures were applied to reduce gradients in soil water content between sampling depths.

In different investigations, sampling the soil every $2.5 \mathrm{~cm}$ or even more starting from the surface was considered enough to capture the vertical variability of SWR at a given point (e.g., Tessler et al., 2008; Dekker et al., 2001, 2009; Keizer et al., 2008; Oostindie et al., 2017). However, this investigation suggested that great vertical SWR gradients can occur at even smaller vertical distances such as, for example, a decrease of SWR from extreme to strong in the passage from a sampling depth of $-1 \mathrm{~cm}$ to $-2 \mathrm{~cm}$ (site 55a, Figure 1C) or from strong to slight in the passage from 3 to $-4 \mathrm{~cm}$ at both sites. Therefore, working at more closely spaced vertical distances yields details on SWR that cannot be captured otherwise. At least in the laboratory, the suggested depth increment of $1 \mathrm{~cm}$ (Wallach et al., 2005; Graber et al., 2006; Weninger et al., 2019) appears practical and also appropriate to detect short-scale vertical changes in SWR.

\section{Soil water content}

According to the collected WDPT data, SWR of the undisturbed soil cores was found to increase with $w_{i}$ in the range of the sampled $w_{i}$ values (0.037-0.130 $\mathrm{g} \mathrm{g}^{-1}$, Figure 2). Wettable conditions were only detected for $w_{i}$ values not exceeding $0.057 \mathrm{~g} \mathrm{~g}^{-1}$ and many strong water repellency results were obtained for high $w_{i}$ values. A power relationship between WDPT and $w_{i}$ was found to be usable to describe the data, although the scatter was noticeable (Figure 2). Solving the fitted relationship for $w_{i}$ indicated that the soil was wettable for $w_{i}$ values equal at the most to $0.046 \mathrm{~g} \mathrm{~g}^{-1}$, it was slightly water repellent for $0.046<w_{i} \leq 0.091 \mathrm{~g} \mathrm{~g} \mathrm{~g}^{-1}$, and it became strongly water repellent for larger $w_{i}$ values.

Different relationships between WDPT and $w_{i}$ have been reported in the literature, including those that describe a SWR repellency that increases with soil water content, as in this investigation (de Jonge et al., 1999; Gao et al., 2018). However, both mentioned research groups also recognized that SWR started to decrease as soil water content increased above a certain threshold. The lack of a clear decreasing trend in this experiment does not necessarily signal a different behaviour as compared with the findings by de Jonge et al. (1999) and Gao et al. (2018) since SWR was strong for $w_{i}$ nearly equal to $0.11 \mathrm{~g} \mathrm{~g}^{-1}$ and it was slight for the highest $w_{i}$ value $\left(0.130 \mathrm{~g} \mathrm{~g}^{-1}\right)$. Therefore, the data of Figure 2 could be considered consistent with the mentioned studies although in our case the experimental signs of a decreasing SWR for particularly high soil water contents were fairly weak, albeit detectable, due to the limited experimental information (a single WDPT $v s w_{i}$ data pair) in the range of the highest $w_{i}$ values.

WDPT values that increase with $w_{i}$ were consistent with the field experiment. Perhaps, soil was wettable or SWR conditions were sub-critical (Tillman et al., 1989; Alagna et al., 2019). In this last case, two antagonist factors, i.e. capillarity and hydrophobicity, were simultaneously active at the beginning of the infiltration process. Small WDPTs were obtained in dry soil conditions because capillarity effects predominated. These effects decreased as the soil water content increased and the consequence was that longer WDPTs were measured. Another way to explain the increasing WDPT $v s w_{i}$ relationship could be that, in the laboratory, particularly dry conditions were obtained by placing the soil in an oven at a temperature of $\geq 60^{\circ} \mathrm{C}$ for $48 \mathrm{~h}$. Perhaps, this treatment induced some loss or inactivation of hydrophobic compounds,
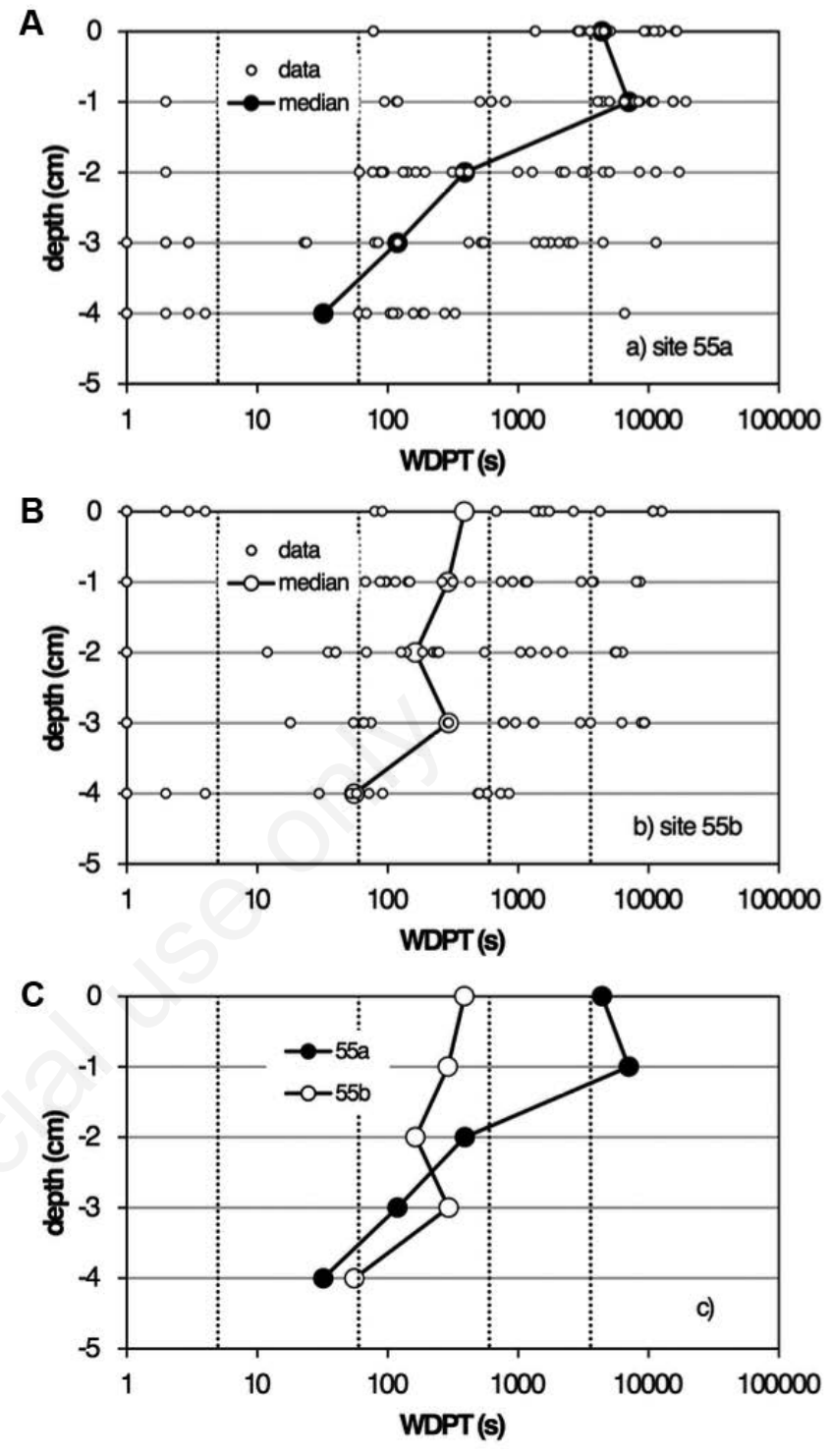

Figure 1. Water drop penetration time (WDPT) values measured at different depths for both the A) 55a and B) 55b sites and C) comparison of the median WDPTs for the 55a and 55b sites.

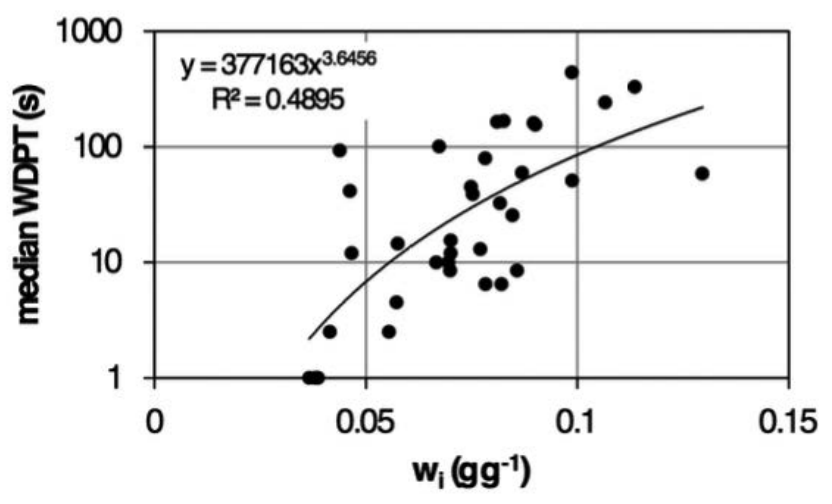

Figure 2. Relationship between the median water drop penetration time (WDPT) and the antecedent gravimetric soil water content, $w_{i}$. 
making the soil more wettable. Of course, these explanations need checks that in any case should also be made with reference to a wider range of soil water contents.

\section{Particle size}

Regardless of the applied method to summarize SWR (modal class, median WDPT value), the fine soil $(<2 \mathrm{~mm})$ was slightly water repellent and a similar result was obtained for the $<0.25 \mathrm{~mm}$, $0.25-0.425 \mathrm{~mm}$ and $0.425-0.85 \mathrm{~mm}$ fractions (Table 4). Instead, wettable conditions were detected for the coarsest soil fraction $(0.85-2.0 \mathrm{~mm})$. The median WDPT for the fine soil, equal to $8.5 \mathrm{~s}$, was intermediate between the corresponding median values for the two finest fractions (13.0-17.0 s) and those for the two coarsest fraction $(1.0-5.0 \mathrm{~s})$. The finest fraction $(<0.25 \mathrm{~mm})$ had a 17 times higher WDPT value than the coarsest fraction $(0.85-2.0 \mathrm{~mm})$. The $O M$ content increased from the coarsest to the finest soil fraction (Table 4) and an increasing relationship between the WDPTs for the four fractions $(<0.25,0.25-0.425,0.425-0.85$ and $0.85-2.0 \mathrm{~mm})$ and their $O M$ content, formally similar to that obtained by Weninger et al. (2019), was recognized (Figure 3). Therefore, a slight SWR of the sieved soil $(<2 \mathrm{~mm})$ was detected because the smallest soil particles $(<0.85 \mathrm{~mm})$ were slightly water repellent.

The mean of the WDPTs for the four soil fractions, weighted by the percentage of each fraction, was equal to $6.0 \mathrm{~s}$ against an arithmetic mean and a median of $9.0 \mathrm{~s}$ and a measured value on the composite soil sample of $8.5 \mathrm{~s}$. Perhaps, this similarity was fortuitous but in any case, it suggested that combining the WDPTs

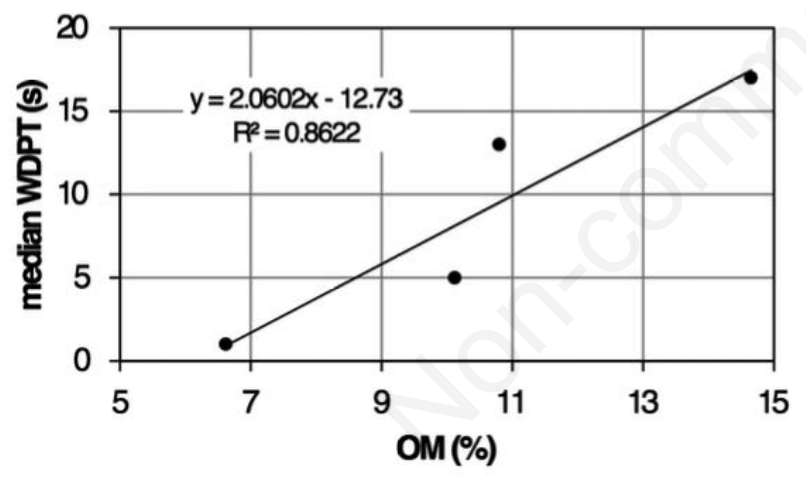

Figure 3. Relationship between the median water drop penetration time (WDPT) for the four textural fractions $(<0.25 \mathrm{~mm}, 0.25-$ $0.425 \mathrm{~mm}, 0.425-0.85 \mathrm{~mm}, 0.85-2.0 \mathrm{~mm}$ ) and the soil organic matter, $O M$, content. obtained on each fraction could yield an information on the expected response of the composite soil sample.

Conceptually similar results, i.e. SWR only for the finest soil textural fractions, were reported in other investigations although, depending on land use, all soil fractions can also exhibit some degree of SWR (Bisdom et al., 1993; Rodríguez-Alleres et al., 2007). More water repellency in the finest soil fractions as a consequence of a higher $O M$ content was also reported by de Jonge et al. (1999) and, more recently, by Rodríguez-Alleres et al. (2007) for soils under maize crop and grassland.

Due to the natural reserve area regulations, soil for the particle size effect experiment was unavoidably collected from the upper 0.03-0.04 $\mathrm{m}$ that exhibited strong vertical gradients in SWR (Figure 1). Therefore, a likely reason of the particularly low WDPT values was that some kind of dilution effect occurred at the sampling time, i.e. the soil used for this investigation was a mixture of particles with different degrees of SWR. Other explanations could however be possible such as those listed by Graber et al. (2006) and Weninger et al. (2019), who suggested that sample disturbance can decrease the detectable SWR due to the effects on surface roughness, pore size distribution, pore connectivity, soil bulk density, distribution and orientation of materials responsible for repellency.

\section{Conclusions}

Establishing how SWR evolves after the passage of fire in a given area is important to take decisions on how to contrast degradation processes that are likely in burned areas. In most instances, the first assessment of SWR in a fire affected area is carried out after the passage of the fire, which implies that the pre-fire conditions are generally unknown.

This investigation showed that, starting from a severe SWR after the passage of a fire, different results can be obtained two years later, that is detection of wettable soil conditions, persistence of SWR at a smaller level, and maintenance of similar levels of SWR between the two sampling years. Both the decrease and the vanishing of any SWR can be interpreted as a sign that the SWR measured after the passage of the fire was really a consequence of burning. Detection of persisting SWR levels induces to be more prudent in formulating a similar conclusion because a possibility is that recovery of pre-fire conditions is locally slow, i.e. it occurs on a longer period than the considered one. However, it cannot be excluded that fire did not have any effect and the soil was water repellent for other reasons. Therefore, in the absence of any information on pre-fire SWR levels, sampling the soil both immediately after the passage of the fire and two years later should be expected to be appropriate for distinguishing between sites in which one can

Table 4. Antecedent gravimetric soil water content, $w_{i}$, organic matter, OM, content, median water drop penetration time (WDPT), soil water repellency class according to both the modal class and the median WDPT procedures for each tested soil fraction.

\begin{tabular}{|c|c|c|c|c|c|}
\hline Parameter & $<2 \mathrm{~mm}$ & $<0.25 \mathrm{~mm}$ & $0.25-0.425 \mathrm{~mm}$ & $0.425-0.85 \mathrm{~mm}$ & $0.85-2.0 \mathrm{~mm}$ \\
\hline$w_{i}\left(\mathrm{~g} \mathrm{~g}^{-1}\right)$ & 0.1278 & 0.1235 & 0.1329 & 0.1204 & 0.1009 \\
\hline OM (\%) & n.d. & 14.6 & 10.8 & 10.1 & 6.6 \\
\hline Median WDPT (s) & 8.5 & 17.0 & 13.0 & 5.0 & 1.0 \\
\hline SWR class (modal class) & SLI & SLI & SLI & SLI & WET \\
\hline SWR class (median WDPT) & SLI & SLI & SLI & SLI & WET \\
\hline
\end{tabular}

n.d., not determined; WDPT, water drop penetration time; SWR, soil water repellency. 
confidently believe that SWR developed as a consequence of the fire and sites in which this conclusion cannot be made.

Large gradients in WDPTs over small vertical distances, smaller WDPT values in drier soil conditions, and less water repellency in the coarsest soil textural fraction were reported in this investigation. As a consequence, it was suggested that: i) capillarity effects could prevail over water repellency effects at very low soil water contents; ii) placing the soil samples in an environment with a reduced biological activity could determine a decrease of SWR, and iii) mixing water repellent and wettable soil has to be taken into account when disturbed soil is collected in the field for laboratory assessment of SWR.

Values of the WDPT that decrease as the antecedent soil water content increases are more easily explainable by a SWR-based reasoning as compared with WDPT values that instead decrease in drier soil conditions. Better establishing what kind of information is really obtained in this last case is necessary because smaller infiltration times in initially drier soils are consistent with the classical physics of infiltration in wettable porous media. According to this investigation, a topic needing development is establishing if this kind of relationship is a consequence of a reduced biological activity of the soil.

Experimental investigations on post fire dynamics of SWR are still rather uncommon probably because they imply long to very long sampling campaigns, i.e. of several or even many years. However, these investigations should be carried out in different environments in an attempt to better explain temporal changes of SWR after the passage of the fire. In this investigation, the laboratory experiments allowed us to both support field results (soil water content effects, small scale spatial variability of SWR) and to test factors for which a field investigation was not easy (depth effects) or even impossible (particle size effects). Therefore, performing simultaneously field and laboratory assessments on SWR is useful to strengthen the experimental information on the processes under study.

\section{References}

Alagna V, Iovino M, Bagarello V, Mataix-Solera J, Lichner L. 2017. Application of minidisk infiltrometer to estimate water repellency in Mediterranean pine forest soils. J. Hydrol. Hydromech. 65:254-63.

Alagna V, Iovino M, Bagarello V, Mataix-Solera J, Lichner L. 2019. Alternative analysis of transient infiltration experiment to estimate soil water repellency. Hydrol. Process. 33:661-74.

Bisdom EBA, Dekker LW, Schoute JFT. 1993. Water repellency of sieve fractions from sandy soils and relationships with organic material and soil structure. Geoderma 56:105-18.

Bryant R, Doerr SH, Hunt G, Conan S. 2007. Effects of soil compaction on soil surface water repellency. Soil Use Manage. 23:238-44.

de Jonge LW, Jacobsen OH, Moldrup P. 1999. Soil water repellency: effects of water content, temperature, and particle size. Soil Sci. Soc. Am. J. 63:437-42.

Dekker LW, Doerr SH, Oostindie K, Ziogas AK, Ritsema CJ. 2001. Water repellency and critical soil water content in a dune sand. Soil Sci. Soc. Am. J. 65:1667-74.

Dekker LW, Ritsema CJ, Oostindie K, Moore D, Wesseling JG. 2009. Methods for determining soil water repellency on fieldmoist samples. Water Resour. Res. 45:W00D33.

Doerr SH. 1998. On standardizing the 'Water Drop Penetration
Time' and the 'Molarity of an Ethanol Droplet' techniques to classify soil hydrophobicity: A case study using medium textured soils. Earth Surf. Proc. Land. 23:663-8.

Doerr SH, Thomas AD. 2000. The role of soil moisture in controlling water repellency: new evidence from forest soils in Portugal. J. Hydrol. 231-2:134-47.

Doerr SH, Shakesby RA, Walsh RPD. 2000. Soil water repellency: its causes, characteristics and hydro-geomorphological significance. Earth-Sci. Rev. 51:33-65.

Doerr SH, Shakesby RA, Blake WH, Chafer CJ, Humphreys GS, Wallbrink PJ. 2006. Effects of differing wildfire severities on soil wettability and implications for hydrological response. J. Hydrol. 319:295-311.

Doerr SH, Shakesby RA, MacDonald LH. 2009. Soil water repellency: a key factor in post-fire erosion. In: A. Cerdà, P. Robichaud (Eds.), Fire effects on soils and restoration strategies. Science Publishers, Enfield, NH, USA pp 197-223.

Gao Y, Lin Q, Liu H, Wu H, Alamus. 2018. Water repellency as conditioned by physical and chemical parameters in grassland soil. Catena 160:310-20.

Gee GW, Bauder JW. 1986. Particle-size Analysis. In: SSSA Book Series, A. Klute (Ed.), Methods of soil analysis, Part 1: Physical and mineralogical methods. Soil Science Society of America, American Society of Agronomy, Madison, WI, USA pp 383-411.

Gordillo-Rivero AJ, García-Moreno J, Jordán A, Zavala LM, Granja-Martins FM. 2014. Fire severity and surface rock fragments cause patchy distribution of soil water repellency and infiltration rates after burning. Hydrol. Process. 28:5832-43.

Graber ER, Ben-Arie O, Wallach R, 2006. Effect of sample disturbance on soil water repellency determination in sandy soils. Geoderma 136:11-9.

Hallin I, Douglas P, Doerr SH, Bryant R, 2013. The role of drop volume and number on soil water repellency determination. Soil Sci. Soc. Am. J. 77:1732-43.

Iovino M, Pekárová P, Hallett PD, Pekár J, Lichner L, MataixSolera J, Alagna V, Walsh R, Raffan A, Schacht K, Rodný M. 2018. Extent and persistence of soil water repellency induced by pines in different geographic regions. J. Hydrol. Hydromech. 66:360-8.

Keizer JJ, Doerr SH, Malvar MC, Prats SA, Ferreira RSV, Oñate MG, Coelho COA, Ferreira AJD. 2008. Temporal variation in topsoil water repellency in two recently burnt eucalypt stands in north-central Portugal. Catena 74:192-2004.

Larson-Nash SS, Robichaud PR, Pierson FB, Moffet CA, Williams CJ, Spaeth KE, Brown RE, Lewis SA. 2018. Recovery of small-scale infiltration and erosion after wildfires. J. Hydrol. Hydromech. 66:261-70.

Letey J, Carrillo MLK, Pang XP. 2000. Approaches to characterize the degree of water repellency. J. Hydrol. 231-232:61-5.

Lilliefors HW, 1967. On the Kolmogorov-Smirnov test for normality with mean and variance unknown. J. Am. Stat. Assoc. 62:399-402.

Lichner L, Felde VJMNL, Büdel B, Leve M, Gerke HH, Ellerbrock RH, Kollár J, Rodný M, Šurda P, Fodor N, Sándor R. 2018. Effect of vegetation and its succession on water repellency in sandy soils. Ecohydrology. 11:e1991.

Oostindie K, Dekker LW, Wesseling JG, Geissen V, Ritsema CJ. 2017. Impact of grass removal on wetting and actual water repellency in a sandy soil. J. Hydrol. Hydromech. 65:88-98.

Robichaud PR, Wagenbrenner JW, Lewis SA, Ashmun LE, Brown RE, Wohlgemuth PM. 2013. Post-fire mulching for runoff and erosion mitigation. Part II. Effectiveness in reducing runoff 
and sediment yields from small catchments. Catena 105:93-111.

Rodríguez-Alleres M, de Blas E, Benito E. 2007. Estimation of soil water repellency of different particle size fractions in relation with carbon content by different methods. Sci. Total Environ. 378:147-50.

Tessler N, Wittenberg L, Malkinson D, Greenbaum N. 2008. Fire effects and short-term changes in soil water repellency - Mt. Carmel, Israel. Catena 74:185-91.

Tinebra I, Alagna V, Iovino M, Bagarello V. 2019. Comparing dif- ferent application procedures of the water drop penetration time test to assess soil water repellency in a fire affected Sicilian area. Catena 177:41-48.

Wallach R, Ben-Arie O, Graber ER. 2005. Soil water repellency induced by long-term irrigation with treated sewage effluent. J. Environ. Qual. 34:1910-20.

Weninger T, Filipović V, Mešić M, Clothier B, Filipović L. 2019. Estimating the extent of fire induced soil water repellency in Mediterranean environment. Geoderma 338:187-96. 